\title{
General thoracic surgical training: The future is bright, but there will be bumps ahead
}

\author{
Sandra L. Starnes, MD \\ From the Division of Thoracic Surgery, Department of Surgery, University of Cincinnati College of Medicine, \\ Cincinnati, Ohio. \\ Disclosures: Author has nothing to disclose with regard to commercial support. \\ Received for publication July 21, 2018; accepted for publication July 22, 2018; available ahead of print Aug 29, \\ 2018. \\ Address for reprints: Sandra L. Starnes, MD, John B. Flege Jr. Chair in Cardiothoracic Surgery, University of Cin- \\ cinnati College of Medicine, 231 Albert B. Sabin Way, MC 0558, Cincinnati, OH 45267 (E-mail: sandra. \\ starnes@uc.edu). \\ J Thorac Cardiovasc Surg 2018;156:2388-9 \\ $0022-5223 / \$ 36.00$ \\ Copyright (c 2018 by The American Association for Thoracic Surgery \\ https://doi.org/10.1016/j.jtcvs.2018.07.066
}

In this issue of the Journal, Schieman and colleagues ${ }^{1}$ compare general thoracic surgical training between the United States and Canada. Unlike in the United States, training in cardiac and thoracic surgery in Canada has been independent since $1994 .^{2}$ In Canada, general thoracic training occurs in the context of a 2-year fellowship after a primary residency in general surgery or, less commonly, cardiac surgery, whereas cardiac surgical training is a 6-year primary residency, similar to the integrated 6-year cardiothoracic residency programs in the United States. Although Schieman and colleagues ${ }^{1}$ focus on general thoracic training, it is impossible to separate thoracic and cardiac training in the United States. An overview of the evolution in cardiothoracic training in Canada to independent pathways as well as a comparison between training programs in cardiac surgery, particularly with the integrated 6-year cardiothoracic residency pathway, would be very useful.

After decades of little change in how we educate residents, the last 2 decades have seen a transformation toward competency-based education, which focuses on outcomes rather than on time. This shift started with the development of the 6 core competencies, approved in 1999, and more recently progressed to the implementation of the Next Accreditation System in 2013 and 2014. An important part of the Next Accreditation System was the development of specialty-specific milestones, which are competencybased outcomes that residents and fellows should demonstrate as they progress through training. It is uncertain whether the US training programs will ever be fully competency based, with variations in length of training that are based on progression, because of multiple manpower and funding constraints. The Canadian programs, however, will be transitioning to a competency-based system during the next several years.

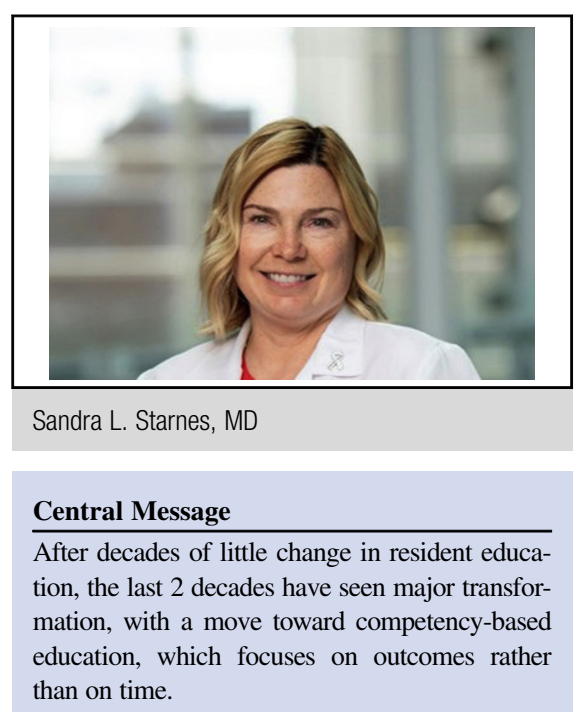

See Article page 2379 .
With only 6 to 8 graduates annually, the Canadian system allows more uniformity in thoracic surgical training. On the other hand, there is significant variability in cardiothoracic training in the United States. Although some of this variability is unavoidable, there are ways to improve the consistency. The Thoracic Surgical Curriculum, managed by the Society of Thoracic Surgeons, provides a structured didactic program, along with a vast library of on-line resources. There has been significant variation, however, in adoption by programs. With continued refinement of the Curriculum and ongoing education of program directors and faculty in its use, it is to be hoped that we will see more consistency in the implementation. The accurate assessment of competence is one of the challenges of competency-based education. The availability and implementation of more standardized assessment tools for the milestones, along with education in the use of these tools, may allow for more reliability and consistency in competency assessment. Finally, it is critical to assess the outcomes of the new training paradigms. There is even more variability among integrated 6-year cardiothoracic residency programs than in the traditional programs, particularly in the junior years, with no standardized curriculum or format. With only a small number of graduates thus far, the outcomes are yet unproven. 
We are facing significant change in the education of the next generations of thoracic surgeons, but at the same time, we have an opportunity to have a large impact on the future of our specialty. The future is bright, but there will be bumps ahead.

\section{References}

1. Schieman C, Seder CW, D'Amico TA, Grondin SC. General thoracic surgica training in North America: contrasting general thoracic surgery residencies in Canada and the United States. J Thorac Cardiovasc Surg. 2018;156:2379-87.

2. Noly PE, Rubens FD, Ouzounian M, Quantz M, Shao-Hua W, Pelletier M, et al Cardiac surgery training in Canada: current state and future perspectives. $J$ Thorac Cardiovasc Surg. 2017;154:998-1005. 